\title{
ALGUNAS CONSIDERACIONES SOBRE LA TRANSFERENCIA MITOCONDRIAL: ¿UN NUEVO PROBLEMA PARA LA BIOÉTICA?
}

\author{
Iñigo De Miguel Beriain ${ }^{1}$, Elena Atienza Macías ${ }^{1}$, Emilio José Armaza Armaza ${ }^{1}$ \\ Resumen: En febrero de 2015 el Reino Unido dio el primer paso para la aprobación de la transferencia mitocondrial como \\ técnica terapéutica. Teóricamente, gracias a eso será posible para muchas mujeres engendrar descendencia libre de patologías \\ asociadas a defectos mitocondriales. Sin embargo, esta práctica enfrenta severas dudas desde un punto de vista ético. Entre \\ las objeciones destacan: su estrecha vinculación con la clonación humana; la alteración de los genes de la línea germinal; la \\ modificación de la identidad del ser humano al que dará lugar; la destrucción de embriones humanos que envuelve, o el elevado \\ riesgo que encierra para la salud del ser humano resultante. En este texto se analiza la solvencia de todas estas objeciones de \\ forma crítica, resaltando las fortalezas de algunas de ellas. En particular, se aboga por una restricción cuidadosa del uso de esta \\ técnica, que promueva el empleo de alternativas más respetuosas con la salud del futuro ser humano.
}

Palabras clave: reemplazo mitocondrial, clonación, diagnóstico genético preimplantatorio, terapias génicas

Some thoughts on the mitochondrial transfer: a new issue for bioethics?

Abstract: In February 2015 the United Kingdom took the first step towards the adoption of mitochondrial transfer as a therapeutic technique. Theoretically, it will make it possible for many women to get rid of pathologies associated with mitochondrial defects. However, this practice has been subjected to severe doubts from an ethical standpoint. Among these objections, we could highlight the following: its close association with human cloning; the alteration of the germline genes; the modification in the identity of the human being involved; the destruction of human embryos; or the high risk to the health of the human being. In this text we will analyze these objections critically, highlighting the strength of all of them. As a result, we will call for a careful restriction of the use of this technique, and the promotion of the use of alternative options much more respectful of the human future.

Key words: mitochondrial transfer, cloning, preimplatatory genetic diagnosis, gene therapies

Algumas consideraçóes sobre a transferência mitocondrial: um novo problema para a bioética?

Resumo: Em fevereiro de 2015 o Reino Unido deu o primeiro passo para a aprovação da transferência mitocondrial como técnica terapêutica. Teoricamente, graças a isso será possível a muitas mulheres engendrar descendência livre de patologias associadas a defeitos mitocondriais. No entanto, esta prática enfrenta severas dúvidas a partir de um ponto de vista ético. Entre as objeçôes destacam: sua estreita vinculação com a clonagem humana; a alteraçáo dos genes da linha germinal; a modificação da identidade do ser humano ao qual dará lugar; a destruição de embriôes humanos que envolve, ou o elevado risco que encerra para a saúde do ser humano resultante. Neste texto se analisa a solvência de todas estas objeçôes de forma crítica, ressaltando as fortalezas de algumas delas. Em particular, se advoga por uma restriçáo cuidadosa do uso desta técnica, que se promova o emprego de alternativas mais respeitosas com a saúde do futuro ser humano.

Palavras-chave: substituição mitocondrial, clonagem, diagnóstico genético pré-implantacional, terapias gênicas

\footnotetext{
${ }^{1}$ Cátedra Interuniversitaria de Derecho y Genoma Humano, Universidad de Deusto y Universidad del País Vasco UPV/EHU, Bilbao, Espańa

Correspondencia: inigo.demiguel@deusto.es
} 


\section{Introducción}

El 3 de febrero de 2015 la Cámara de los Comunes del Reino Unido aprobó, por 382 votos a favor y 128 en contra, una modificación de la Ley de Embriología y Fertilización Humana de 2008, que permitirá la realización de la denominada "trasferencia mitocondrial" en seres humanos. Es probable que, de otro lado, Estados Unidos emprenda una vía similar, dado que la Federal Drug Administration está ahora mismo planteándose seriamente aceptar el uso terapéutico de esta tecnología(1).

Ante esta evidencia ha arreciado un debate ético entre dos posturas claramente enfrentadas. De un lado se hallan quienes aplauden la aplicación de la transferencia mitocondrial, que consideran una técnica de carácter marcadamente terapéutico, por cuanto puede suponer un avance decisivo para aquellas mujeres incapaces de tener hijos por un $\mathrm{ADN}$ mitocondrial defectuoso. Frente a ellos, no obstante, hay una corriente que plantea cuestiones extremadamente graves acerca de la legitimidad de la aplicación de este método, sobre diferentes bases: las destrucción de vidas humanas en fase embrionaria, la ruptura de la prohibición de las modificaciones genéticas en la línea germinal, la inseguridad inherente al procedimiento, la utilización de un proceso de clonación, con todo lo que ello conlleva, etc.

El objetivo de las siguientes páginas será introducir una reflexión crítica sobre esta polémica, tratando de exponer sucintamente las principales objeciones que se han planteado frente a esta práctica para después analizar su verdadera solvencia. Finalmente, intentaremos llegar a unas conclusiones que permitan entender mejor las claves a tener presentes a la hora de enfocar el dilema. Claro que, antes de todo, introduciremos las nociones científicas suficientes como para entender de forma adecuada los parámetros que analizamos.

\section{Cuestiones científicas previas}

La mitocondrias son órganos celulares con un ADN propio y diferente al del núcleo celular. Su misión principal consiste en proveer de energía a la célula. En el caso de un embrión, el buen funcionamiento de la mitocondria supone una condición necesaria para un desarrollo exitoso. Sin embargo, la mitocondria puede desarrollar más de 150 patologías diferentes, como la enfermedad de Luft o la neuropatía óptica hereditaria de Leber(2). Algunas de ellas tienen lugar por la influencia de factores externos, pero otras se hallan ligadas directamente a un ADN mitocondrial defectuoso. De ahí que tenga sentido pensar en la posibilidad de recurrir a la transferencia mitocondrial como forma de proporcionar una solución eficiente a este problema.

Ahora mismo, la forma como afrontarse esta clase de problemas no es otra que la realización de diagnósticos genéticos preimplantatorios, destinados a analizar la calidad del ADN mitocondrial. Una vez realizada la prueba, se transfieren al útero materno exclusivamente los embriones sanos, mientras se desechan los que muestran alteraciones genéticas. El desarrollo de las técnicas de reemplazo mitocondrial supone, a juicio de sus defensores, una manera mucho más eficiente de dar respuesta a esta necesidad clínica, por cuanto ya no sólo se hace innecesaria la constitución de embriones defectuosos, sino que, además, se evita que los embriones sanos tengan que someterse a una prueba que, en último término, puede causarles serios problemas e incluso su destrucción.

En lo que se refiere a la descripción de la técnica de la transferencia, conviene apuntar que, aunque se suele hablar en general de una sola tecnología, lo cierto es que ya se han desarrollado dos procedimientos científicos diferentes destinados a solucionar los problemas mitocondriales. Hay además un tercer método que resulta factible, al menos desde un punto de vista teórico. El primero de ellos consiste en extraer la mitocondria de un óvulo de una mujer que sufre algún tipo de patología asociada a él y reemplazarla por una mitocondria extraída del óvulo de una mujer sana (lo que se denomina Maternal Spindle Transfer, MST). En el segundo caso, el procedimiento consiste en extraer los pronúcleos de un óvulo fertilizado y aquejado de patologías mitocondriales para después introducirlos en otro óvulo previamente enucleado. Se trata, por tanto, de una técnica que actúa en el primer estadio de la existencia humana, esto es, cuando los pronúcleos aún no se han fusionado (Pronuclear Transfer, PT) (3-6). Finalmente, el tercer método parte de la 
posibilidad de utilizar un procedimiento como la transferencia nuclear (Nuclear Transfer, NT) para obtener los mismos resultados. En este caso, se trataría de extraer el núcleo del embrión aquejado por un problema con su ADN mitocondrial para después transferirlo a otro embrión previamente enucleado. Como veremos, las connotaciones de unos casos y otros no serán las mismas.

\section{¿Una forma de clonación?}

Una crítica habitual a la transferencia mitocondrial es que constituye una forma de clonación $(7,8)$. De hecho, ya hace muchos años en la literatura académica en castellano se habla de la "paraclonación" $(9,10)$ para denominar a la transferencia mitocondrial. Discernir si esto se ajusta o no a la realidad tiene importantes implicaciones, tanto desde un punto de vista ético como legal. En el primero de ambos casos se arguye que la aceptación de una forma de clonación no es ya solo inadmisible en sí misma, sino también porque traerá inevitablemente como consecuencia la progresiva implantación de otras variantes. Por tanto, se aduce, admitir el reemplazo mitocondrial sería tanto como dar luz verde a la producción de los primeros clones humanos. A todo lo anterior hay que sumar el argumento que apela a la ilegalidad manifiesta de la técnica. Así, se sugiere a menudo que, dado que la paraclonación es una forma de clonación, resulta claramente ilegal, siendo incluso perseguible en algunos países en el ámbito penal.

Esta crítica, no obstante, adolece de numerosos defectos que la hacen particularmente fallida. Para empezar, se centra en una técnica, el trasplante de núcleo embrionario (Nuclear transfer, NT), que actualmente no se utiliza en transferencia mitocondrial. Pero, aunque se diera el caso de que un día la ciencia utilizara esta tercera tecnología, seguiría sin ser un caso de clonación. Y es que la crítica citada confunde técnica con finalidad, herramienta con producto. La transferencia nuclear es, por sí, una técnica que puede utilizarse con diferentes finalidades. Por ejemplo, se emplea para la obtención de líneas celulares susceptibles de uso terapéutico. Pensar que esto equivale a una clonación es complejo, por cuanto clonar es una acción encaminada a una finalidad concreta: la producción de un ser semejante a otro que ya existe. Cuando usamos la transferencia nuclear para producir líneas celulares estamos muy lejos de perseguir ese objetivo. Mucho más lo estamos todavía en un caso como el de la transferencia mitocondrial, en el que hablar de clónico y clonado resulta extremadamente complejo, por inverosímil(11). Lo que de verdad ocurre es que a una entidad, sea un óvulo o un embrión, se le transfiere la mitocondria. Suponer que en este proceso se acaba clonando un ser humano resulta, cuando menos, sumamente aventurado(3). A todo ello hay que sumar, por descontado, que a diferencia de lo que ocurre en la transferencia nuclear, que se utiliza para clonar mamíferos (SCNT o somatic cell nuclear transfer), aquí no se emplea en ningún momento una célula somática, sino que se opera siempre sobre el propio óvulo o embrión que necesita la transferencia y un óvulo humano. Con lo que, incluso desde un punto de vista estrictamente científico, la diferencia es notoria entre ambos $\operatorname{casos}(12-16)$.

La única conclusión razonable es que, desde un punto de vista ético, el argumento es más que cuestionable, mientras que, desde el punto de vista legal, resulta claramente insuficiente. $\mathrm{Y}$ es que no debemos olvidar que, para que el derecho penal actúe es necesaria la concreción de una conducta antijurídica y culpable que no ofrezca dudas. Y este caso está, precisamente, plagado de dudas. Por tanto, concluiremos que si hemos de oponernos a la transferencia nuclear no será sobre esta endeble base.

\section{Un atentado contra la identidad del ser humano}

Otra de las objeciones planteadas frente a la transferencia mitocondrial es que supone un grave atentado contra la identidad del ser humano resultante. Este argumento se enraíza sobre la suposición de que cuando cambiamos el ADN mitocondrial estamos alterando sustancialmente los factores que confluyen en la construcción de la identidad del ser humano, como ha argumentado Maureen Condic(8). Dado que, en general, consideramos la identidad como un bien, como algo inherentemente valioso, en cuanto que constituye la esencia misma del ser humano, la transferencia mitocondrial resulta inadmisible desde un punto de vista moral. 
Este argumento, no obstante, es difícilmente aceptable por varios motivos. Empecemos por lo más obvio: en el caso del reemplazo anterior a la conclusión de la fecundación, resulta imposible hablar de identidad por la sencilla razón de que no existe todavía un individuo cuya identidad se pueda alterar. En este sentido, alterar el óvulo que se utilizará en la fecundación supondrá, por supuesto, determinar que el individuo creado sea diferente al que hubiese surgido caso de que no se habría producido la alteración. Pero eso no significa en absoluto que se altere una identidad, porque para hablar de alteración resulta imprescindible pensar en una entidad previamente existente que alterar, lo que aquí no sucede. Con lo cual es evidente que en este primer caso no existe cambio en la identidad del ser humano.

¿Y qué decir del caso de un embrión ya constituido? En esta ocasión es claro que sí existe una identidad que puede ser alterada. Otra cosa, sin embargo, es aceptar que un cambio en el ADN mitocondrial sea, por sí mismo, lo suficientemente poderoso como para causar tal efecto. $Y$ es que si pensamos que la identidad es tanto como lo que nos hace ser nosotros mismos y no otros, resulta muy complejo concluir que sea posible alterar tan drásticamente nuestra esencia como Condic supone. Pongamos un ejemplo. Como es también conocido, el ambiente uterino o el lugar donde un embrión se ha situado dentro del cuerpo de la mujer constituyen elementos decisivos para determinar su concreto desarrollo. Sin embargo, prácticamente nadie se atrevería a afirmar que un cambio como, por ejemplo, un movimiento brusco de la ubicación del embrión, causaría una alteración crítica en su identidad. Entre otras cosas, porque hay una gran diferencia entre afirmar que un hecho posee influencia en nuestro desarrollo y sostener que la influencia llega hasta el extremo de desposeernos de nuestra identidad. Probablemente un ADN mitocondrial diferente hará que el desarrollo del embrión conozca cambios importantes, pero de ahí a considerar que ese embrión ya no será él mismo hay una enorme diferencia.

Por último, aunque así fuera, esto es, aunque aceptáramos que se produce ese cambio de identidad, todavía resultaría excesivo aceptar que tal circunstancia sería siempre y en toda circunstancia moralmente inaceptable. Esto resulta especialmente cierto si pensamos que un embrión sufre de una patología capaz de deteriorar sustancialmente la vida del ser humano al que dará lugar. ¿Realmente estaríamos haciendo algo malo si eliminásemos esa patología, aun a costa de cambiar la identidad de ese embrión? ¿Qué preferiría ese embrión? ¿Ser él mismo, gravemente enfermo, pero con su identidad, o ser otro ser humano, pero sano? La respuesta a estas preguntas dista de ser clara.

\section{La destrucción de embriones humanos}

Otra crítica de gran peso al reemplazo mitocondrial es la que sostiene que al menos una de las dos técnicas que se utilizan para el reemplazo mitocondrial exige la destrucción de un óvulo humano fecundado que se encuentra en las primeras fases de su desarrollo, esto es, el momento en el que los dos pronúcleos aún no se han fusionado. Para muchos autores, estas entidades deberían ser consideradas ya embriones humanos, por cuanto la vida humana comienza en el mismo momento en que un espermatozoide penetra en un óvulo(17-19). En consecuencia, el reemplazo mitocondrial ocasionaría, al menos en el caso de la técnica de la transferencia pronuclear (PT), la muerte deliberada de un ser humano, lo que resulta absolutamente inadmisible desde un punto de vista ético.

Argumento de enorme peso específico, cuenta sin embargo con numerosos problemas teóricos. El primero de ellos es que exige que se comparta la idea de que todo embrión humano es valioso por sí mismo, lo que está lejos de ser pacíficamente admitido. Pero es que, incluso aunque compartiéramos este razonamiento, hay motivos de peso por los que considerar que una entidad en la que aún no se ha producido la fusión pronuclear no es todavía un embrión humano(20-22). Piénsese a este respecto que entre las horas que transcurren desde la entrada del espermatozoide en el óvulo hasta la fusión de los pronúcleos no existirá ningún ser con un ADN propio. Si buceáramos en su interior, hallaríamos dos ADN distintos, uno similar al de su padre y otro al de su madre, sin ninguna huella de identidad propia. Pretender que un sujeto sea racional en un momento en que, como tal, ni siquiera existe tal sujeto, ni hay ninguna forma, modelo o mecanismo de saber qué o cómo será, resulta cuando menos un tanto complejo, nos tememos. 
De ahí que muchos de quienes defienden el carácter sagrado del embrión humano consideren, a un tiempo, que no es la entrada de un espermatozoide en un óvulo sino la fusión de los pronúcleos gaméticos lo que fija el inicio de la vida humana, postura además que es la que figura en un documento de la importancia de la Donum Vitae y que ha sido asumida por las legislaciones de algunos de los países europeos más relevantes. De este modo, por ejemplo, la HFEA británica, de 1990, señala que "a) embrión significa un embrión humano vivo en el que la fertilización se ha completado y b) las referencias al embrión incluyen al huevo durante el proceso de fertilización y, en lo que a ello se refiere, la fertilización no se completa hasta la aparición del cigoto de dos células". Del mismo modo, la Ley de Protección del Embrión, No 745/90 del 13/12/90, de Alemania, establece: "Art. 8.- Definiciones. 1. En el espíritu de la presente ley, hay 'embrión' desde que hay fecundación y susceptibilidad de desarrollo del óvulo fecundado, a partir de la fusión de los núcleos celulares. El mismo término se aplica a toda célula totipotente extraída de un embrión, susceptible de dividirse si se reúnen las otras condiciones necesarias, y desarrollarse hasta formar un individuo. 2. El óvulo humano fecundado se entiende susceptible de desarrollo en el curso de las primeras 24 horas siguientes a la fusión de los núcleos celulares, a menos que se hubiera constatado, antes del transcurso de este período, la imposibilidad para el óvulo fecundado de desarrollarse más allá del estadio unicelular”.

Si esto es así, la fortaleza del argumento elaborado para oponerse a la transferencia mitocondrial resulta absolutamente mermada: si no hay embrión, es obvio que no hay destrucción de embrión. Con todo, concederemos, parece razonable priorizar, siempre que sea posible, la técnica de la MST sobre la PT, de manera que sea un óvulo sin fecundar y no otro ya fecundado el objeto de la manipulación. ¿Y qué ocurriría en el caso de que algún día se utilizara la transferencia nuclear para el reemplazo mitocondrial? En este caso, nos tememos, el diagnóstico tendría que ser claramente diferente, por cuanto esta variante implica necesariamente la destrucción de un embrión sano, aquel del que se extrae el núcleo, para solucionar un problema que afecta a otro. Si consideramos que el embrión es un ser humano, tal conducta sería equivalente al sacrificio de un ser humano sano para trasplantar sus órganos a otros que se hallan enfermos, lo que es sin duda aberrante. En tales circunstancias, no hay duda de que la consideración axiológica que nos merezca el embrión condicionará absolutamente la admisibilidad o no de esta técnica, pero resulta evidente que esta modalidad resulta mucho más polémica — desde el punto de vista del respeto debido al embrión- que las dos anteriores.

Por último, hay que reseñar un dato muy importante en lo que se refiere a la salvaguarda de la vida humana. Como hemos indicado ya, la forma en que actualmente se lucha contra las patologías ligadas al $\mathrm{ADN}$ mitocondrial es la realización de un diagnóstico genético preimplantatorio, seguido de la selección de los embriones sanos. Evidentemente, esta forma de proceder hace que se descarten sistemáticamente multitud de embriones enfermos, a la par que causa a veces la muerte de embriones sanos por la agresividad que envuelve el diagnóstico. La transferencia mitocondrial permitiría evitar estas terribles disfunciones, lo que significaría ahorrar muchas vidas embrionarias. Por tanto, y siguiendo estrictamente este criterio, habría que convenir que, al menos en el caso de las transferencias realizadas antes de la fecundación o aun de las que tienen lugar en el estadio pronuclear, la técnica podría incluso considerarse como recomendable, si nos atenemos exclusivamente al criterio de salvaguarda de la vida embrionaria.

\section{La modificación del ADN en la línea germinal}

A continuación reseñaremos una de las críticas fundamentales que se hace a la transferencia mitocondrial, aquella que la acusa de introducir inevitablemente una modificación del ADN que se transmite a las siguientes generaciones, esto es, el ADN en la línea germinal(8). De acuerdo con esta crítica, no deberíamos proseguir con estas prácticas por cuanto estaremos poniendo en peligro ya no solo la vida o la salud de los seres humanos sobre las que se efectúan, sino también las de su descendencia o, incluso, las de la humanidad en su conjunto, dado que es más que probable que dichos genes se esparzan a través de la mezcla biológica inherente a la reproducción humana. 
Frente a esta crítica, los defensores de la transferencia mitocondrial han elaborado varias respuestas. La primera de ellas niega que haya un auténtico cambio en los genes de la línea germinal. Así, por ejemplo, algunos investigadores británicos han argumentado que la transferencia el genoma humano no se modifica por una transferencia mitocondrial. No hay sino un reemplazo, sin que se alteren los genes. De ahí que sea incorrecto hablar de modificaciones genéticas(23). Sin embargo, otros autores(24), así como informes de instituciones tan prestigiosas como el Nuffield Council(3), han rechazado este argumento sobre la base de que se produce una variación en los genes que efectivamente se transmite a la descendencia.

Ahora bien, aunque aceptáramos que efectivamente la transferencia mitocondrial altera los genes de la línea germinal, esto no supone necesariamente que las críticas que habitualmente se hacen a las terapias que afectan a esta línea le sean extensivas. Hay poderosos motivos por los que trazar diferencias sustanciales entre este caso y todos los demás. El primero de ellos es que la propia naturaleza de la técnica provoca una alteración mucho menor en los genes que otras técnicas, por lo que los riesgos más significativos que asociamos a la modificación de la línea germinal no son aplicables a esta situación(3). En segundo lugar, no es lo mismo modificar el ADN mitocondrial que el nuclear, porque ambos afectan a materiales muy diferentes. Mientras que el segundo determina rasgos esenciales de nuestra personalidad, el primero nunca provocará el mismo efecto. De ahí que sea perfectamente posible establecer nítidas diferencias entre la alteración de uno y otro $\mathrm{ADN}$, incluso desde un punto de vista legal(3).

Resulta conveniente, en todo caso, tener presente la solidez de un argumento presentado por los detractores de esta técnica: la aceptación de la transferencia mitocondrial introducirá una enorme presión para la legalización de otras formas de modificación de la línea germinal. Las apelaciones a la idea de la "pendiente resbaladiza" resultan particularmente razonables en este caso. Como sea, y dado que esta objeción alude en gran medida al riesgo terapéutico que envuelve la aceptación de esta técnica, nos remitiremos ahora al siguiente y último epígrafe, en el que trataremos precisamente este problema.

\section{Reemplazo mitocondrial, riesgo y salud}

La primera y tal vez más notoria crítica al reemplazo mitocondrial, es la que alude al riesgo que una operación de estas características implica sobre el ser humano al que dará lugar (caso de que se realice sobre óvulo) o sobre el que ya existe (caso de que se efectúe sobre un óvulo fecundado o un embrión). Los detractores de esta técnica han puesto de manifiesto que todavía desconocemos si producirá o no efectos negativos en los seres humanos que generarán los óvulos o embriones que ahora modifiquemos, y si estas consecuencias se arrastrarán a generaciones posteriores, dado que afectan al ADN en la línea germinal. Aún no sabemos, por ejemplo, si la convivencia de dos $\mathrm{ADN}$ diferentes — mitocondrial y nuclear — será inocua, ni tampoco si algunos de los instrumentos que se utilizan en el proceso - como el Nocodazole o el virus Sendai- producen o no consecuencias a largo plazo(4). De ahí que, a su juicio, sea necesario posponer su aplicación, como ya hizo la FDA en 2003, cuando Jamie Grifo intentó llevar a término un reemplazo mitocondrial. Frente a esta objeción, los defensores de la técnica han subrayado que las garantías que ofrece la ciencia son ahora sustancialmente mejores que en ańos anteriores, dado que los experimentos realizados con simios han sido significativamente exitosos y su riesgo observado escaso $(5,6)$.

Siendo cierta esta apreciación, no debemos dejar de lado la evidencia de que solo será posible conocer los resultados reales de la técnica en humanos cuando esta empiece a utilizarse. Y, efectivamente, es posible que algunos de los primeros seres humanos a los que dé origen sufran algún tipo de alteración negativa como consecuencia, lo que no ha de ser en ningún caso un factor desdeñable a la hora de encarar el debate. Ahora bien, ¿quiere esto decir que deberíamos suspender indefinidamente el uso terapéutico de esta técnica? Llegar a una conclusión tan general resulta complejo. A fin de cuentas, todo procedimiento biomédico novedoso encierra un riesgo. Baste al respecto pensar en el elevadísimo grado de incertidumbres que encerraba la fecundación in vitro cuando empezó a efectuarse y, sin embargo, los temores que entonces generaba nunca se plasmaron realmente. Más aún, debemos tener presente que el concepto de riesgo nulo no existe en la ciencia. En consecuen- 
cia, una prohibición basada únicamente en este parámetro haría en la práctica inviable el progreso médico. La cuestión consiste en saber qué grado de riesgo puede resultar aceptable. Si las agencias oficiales consideran que este lo es, deberíamos aceptar su criterio, al menos a primera vista.

Esto, no obstante, tampoco debería significar una autorización generalizada de esta práctica como la que parece va a producirse en el Reino Unido. En el caso de los fármacos, la fase de ensayos clínicos necesita completarse adecuadamente antes de permitir un uso masivo de la nueva droga. Sería interesante sugerir que siguiéramos una misma dinámica con el trasplante mitocondrial. Por desgracia, esta sugerencia resulta en buena medida irrealizable, porque el plazo de aparición de posibles consecuencias negativas se prolonga hasta varias generaciones después de la realización de la técnica, debido a la alteración producida en el ADN mitocondrial. Sin embargo, esto no significa que no se puedan adoptar algunas precauciones, que permitan al menos excluir sus riegos más inmediatos y directos, precauciones que además obedecerán a un criterio tanto terapéutico como ético. Una introducción paulatina de la práctica, que permita observar su resultados inmediatos, sería, para empezar, un paso en la dirección correcta. Sobre todo si lo acompaña un seguimiento detallado de cada transferencia por parte de la autoridad sanitaria pertinente. De este modo conseguiríamos al menos limitar las probabilidades de producir un daño notable en el corto plazo. Sin embargo, una aproximación adecuada al seguimiento del riesgo implicará necesariamente lapsos temporales muy amplios, como ya se ha dicho, lo que sin duda complica la cuestión.

En suma, llegar a una conclusión definitiva sobre la valoración del riesgo en el caso de la transferencia mitocondrial no resulta sencillo. De ahí que resulte absolutamente necesario continuar investigando, proporcionar a los progenitores información actualizada y fidedigna y hacer un esfuerzo por llegar a la solución más adecuada para sus intereses y, sobre todo, para los del ser humano a engendrar. Una prohibición generalizada sobre la base del riesgo no parece adecuado ni funcional, al menos si queremos maximizar la protección del ser humano afectado. No debemos olvidar que una política de prohibición puede llevar a que al- gunos progenitores decidan arrostrar el riesgo de una descendencia aquejada de terribles enfermedades ante la perspectiva de poseer su propia descendencia biológica. Por tanto, también, que sea particularmente necesario en este caso utilizar el diálogo como recurso y la responsabilidad como factor esencial a la hora de tomar decisiones que envolverán siempre una incertidumbre de inevitable riesgo(3).

Y en dicho diálogo habrá de enfatizarse necesariamente la existencia de alternativas a la transferencia mitocondrial, como el uso de óvulos donados, que resultan incapaces de satisfacer completamente el deseo de los progenitores por tener una descendencia genéticamente ligada a ellos, pero responden mejor a los intereses del ser humano engendrado. Porque un diálogo solo puede ser provechoso si se incluye también, e incluso por encima de todo, los intereses de los que todavía no son capaces de participar en la discusión, pero que se verán directamente afectados por ella. Y es que, a nuestro juicio, la misma persistencia del riesgo debería llevarnos a considerar que el reemplazo mitocondrial solo debería ser preferible a sus alternativas cuando circunstancias muy concretas así lo aconsejen.

\section{Conclusiones}

A tenor de lo expuesto, creemos ya posible llegar a unas conclusiones razonables. La principal de ellas es que el desarrollo de técnicas de reemplazo mitocondrial que resultan, en principio, suficientemente seguras, deberían impulsarnos a promover su inmediata puesta a disposición de aquellas parejas que sufren graves problemas como consecuencias de patologías asociadas a la mitocondria. Esto parece particularmente razonable en un momento en que un país como el Reino Unido ha tomado ya la decisión de legalizar estas prácticas. La prohibición que existe en otros países bien podría impulsar un "turismo reproductor" en el que, como casi siempre, se acabaría estableciendo una discriminación injusta en función de los niveles de riqueza de los pacientes.

Esta clase de consideraciones no debe enmascarar, no obstante, los problemas que encierra la transferencia mitocondrial. El desconocimiento que todavía poseemos de los resultados a medio 
o largo plazo de la técnica —un problema que no se resolverá a corto plazo-, unido a la evidencia de que los genes modificados se transmiten a la descendencia a través de la línea germinal, son factores que no deben ser infravalorados. De ahí que, como hemos señalado, resulte absolutamente necesario hacer un seguimiento estricto de las transferencias que puedan producirse en los próximos años.

A ello se debe acompañar una declarada intención de ofrecer a los progenitores una información adecuada que subraye los pro y los contra de cada opción terapéutica, incluyendo las alternativas a la transferencia, como la utilización de óvulos donados o la adopción. El objetivo ha de ser siempre un correcto balanceo de los intereses de los progenitores y de los seres humanos a los que sus decisiones darán lugar. Y no debemos olvidar que la transferencia mitocondrial sirve antes al interés de los progenitores por mantener una ligazón genética con su propia estirpe que al interés de su misma descendencia en venir al mundo en el mejor estado de salud que sea posible.

\section{Agradecimientos}

El presente trabajo ha sido confeccionado gracias a la ayuda del Departamento de Educación, Universidades e Investigación del Gobierno Vasco para apoyar las actividades de grupos de investigación (Cátedra Interuniversitaria Diputación Foral de Bizkaia de Derecho y Genoma Humano, Universidad de Deusto y Universidad del País Vasco UPV/EHU) del sistema universitario vasco con referencia IT581-13. 


\section{Referencias}

1. Fox M. Three Parents? FDA Mulls Safety of Embryo Technique. NBC News. Disponible en: http://www.nbcnews.com/ health/kids-health/three-parents-fda-mulls-safety-embryo-technique-n39401

2. HFEA. Scientific review of the safety and efficacy of methods to avoid mitochondrial disease through assisted conception. Report provided to the Human Fertilisation and Embryology Authority, April 2011. Disponible en: http://www.hfea. gov.uk/docs/2011-04-18_Mitochondria_review_-_final_report.PDF

3. Nuffield Council on Bioethics. Novel techniques for the prevention of mitocondrial DNA disorders: an ethical review. Nuffield Council on Bioethics, UK, 2012.

4. Tachibana M, Sparman M, et al. Mitochondrial gene replacement in private offspring and embryonic stem cells. Nature 2009; 461: 367-372.

5. Tachibana M, Amato P, et al. Towards germline gene therapy of inherited mitochondrial diseases. Nature 2013; 493(7434): 627-631.

6. Caplan A. Is it ethical to create babies from three DNA sources? Absolutely, 3 de febrero de 2015. Disponible en: http:// www.wired.com/2015/02/ethical-create-babies-three-dna-sources-absolutely/

7. Eser A, Früwald W, et al. La clonación humana. Fundamentos biológicos y valoración ético-jurídica. Revista de Derecho y Genoma Humano 1998; 9: 91-110.

8. Condic ML. We are not just our DNA: The ethical dangers of three-parent embryos. The Witherspoon Institute 20 de marzo de 2014. Disponible en: http://www.thepublicdiscourse.com/2014/03/12897/

9. Comité de Expertos sobre Bioética y Clonación. Informe sobre clonación. en las fronteras de la vida, Madrid: Fundación de Ciencias de la Salud.

10. Soutullo D. Clonación humana no reproductiva: utilización de embriones para la obtención de tejidos para trasplantes. Revista de Derecho y Genoma Humano 2000; 12: 214.

11. Department of Health. Stem Cell Research: Medical Progress with responsibility. A report from the chief medical officer's expert group reviewing the potential of developments in stem cell research and cell nuclear replacement to benefit human health, June 2000.

12. Sureau C. Come la clonazione reproduttiva umana può cambiare la nostra vita: alcuni scenari. En McLaren A. La clonazione. Uno sguardo etico, Strasbourg: Consejo de Europa: 2002: 85-105.

13. Schüklenk U, Ashcroft R. La ética de la clonación reproductiva y terapéutica. En Palacios M, (coord.) Bioética 2000. Oviedo: NOBEL; 2000: 199-211.

14. Callahan D. Cloning: the work not done. Hastings Center Report 1997; 27(5): 21.

15. Krimsky S, Hubbard R. The business of Research, Hastings Center Report 1995; 25(1): 43.

16. Winston RM, Handyside AH. New challenges in human in vitro fertilization. Science 1993; 260: 932-936.

17. Pardo Caballero A. La determinación del comienzo de la vida humana: cuestiones de método. Cuadernos de Bioética 2007; XVIII: 335-346. Disponible en: http://www.aebioetica.org/rtf/01-BIOETICA-64.pdf.

18. Giuli A. Inizio della vita umana individuale. Basi biologiche e implicazioni bioetiche. Roma: ARACNE; 2005.

19. Pontificia Academia Pro Vita. Identità e statuto dell'embrione umano. Ciudad del Vaticano: Libreria Editrice Vaticana; 1998.

20. Tesaryk J, Greco E. A zygote is not an embryo: ethical and legal considerations. Reprod. Biomed. Online 2004: 9(1): 13-16.

21. Piotrowska K, Zernicka-Goetz M. Role for Sperm in Spatial patterning of the early mouse embryo. Nature 2001; 409: 517-521.

22. Piotrowska K, Wianny F, Pedersen RA, Zernicka-Goetz YM. Blastomeres arising from the first cleavage division have distinguishable fates in normal mouse development. Development 2001; 128: 3739-3748.

23. North East England Stem Cell Institute. Briefing paper on the need to protect the future possibility of treating mitochondrial disease and other conditions by a procedure that involves mitochondrial transplantation. 2008.

24. Mitalipov S, Wolf DP. Clinical and Ethical Implications of Mitochondrial Gene Transfer. Trends Endocrinol Metab 2014; 25(1): 5-7.

Recibido: 12 de febrero de 2015

Aceptado: 10 de marzo de 2015 